\title{
London Trauma and Cardiac Arrest Conference 2013
}

\author{
F Bird $^{1 *}, P$ Avery ${ }^{2}$ \\ From London Trauma Conference 2013 \\ London, UK. 10-13 December 2013
}

The seventh London Trauma Conference was once again held at The Royal Geographical Society in London from $10^{\text {th }}-13^{\text {th }}$ December 2013 . Over four days the latest innovations and best practice in cardiac, trauma and pre-hospital trauma care were presented and discussed. It opened with the London Cardiac Arrest Symposium, kindly sponsored by Zoll, with Dr David Zideman providing the Douglas Chamberlain Lecture; an insightful presentation into the world of Sports Medicine. Over the subsequent three days, delegates heard from internationally acclaimed speakers who addressed key questions relating to trauma, major incident management, and pre-hospital care. Keynote speakers included Professor Dan Davis, Prof Bryan McNally, Mr Michael Crumplin, Mr Justin Lewis and Professor John Pickard. The Norwegian Air ambulance hosted the Air ambulance and pre-hospital care day that reflected on the latest developments, debated best practice and speculated on the future of clinical work in this setting. On the final day, the Peter Baskett Lecture was given by Mr Michael Crumplin, who provided a fascinating over view of the developments in combat trauma care over the last six centuries.

Additional, breakaway sessions took place on each day of the conference. These included Resuscitative Thoracotomy, Practical Cardiac arrest and Neurotrauma masterclasses; Core topics in trauma, a Trauma Research Forum, and the annually anticipated evening of Stand up Science.

Prizes at the conference were awarded as follows;

The most inspiring clinical presentation was awarded to Dr Steen Barnung for his moving and impressive account of a multiple paediatric drowning incident that took place in Denmark.

Best posters: Dr Kate Crewdson and Dr Beth Healey
Stand up Science was won jointly by: Dr's Maria Guerreiro and Hew Torrance.

The innovation prize was won by: Professor Hans Morten Lossius for his work on Pre-hospital stroke thrombolysis.

This year's conference reminded delegates of the potential applications of new technology and innovation in prehospital, trauma and cardiac care but also the importance of ensuring that well established simple interventions are performed reliably and consistently. Once again the conference attracted speakers and delegates from 18 countries and continues to be a forum for learning network and debate. The eighth London conference will take place at the same venue between $9^{\text {th }}-12^{\text {th }}$ December 2014 .

This supplement provides a selection of seven extended abstracts written by speakers at the conference illustrating some of the diverse subject matter covered and also the scientific abstracts from oral and poster presentations made at the conference.

\section{Authors' details \\ ${ }^{1}$ Barts Health NHS Trust, Bart's Health Hospital, London, UK. ${ }^{2}$ London's Air Ambulance, The Royal London Hospital, Whitechapel, London, UK.}

Published: 7 July 2014

doi:10.1186/1757-7241-22-S1-A1

Cite this article as: Bird and Avery: London Trauma and Cardiac Arrest

Conference 2013. Scandinavian Journal of Trauma, Resuscitation and Emergency Medicine 2014 22(Suppl 1):A1.

${ }^{1}$ Barts Health NHS Trust, Bart's Health Hospital, London, UK

Full list of author information is available at the end of the article 